\section{The meaning of Wittgenstein}

SiR--John C. Marshall's resentful ramblings' on the significance of the philosophical heritage of Ludwig Wittgenstein provide little useful information for the uninitiated. The image of Wittgenstein, portrayed under the pretext of a book review, is that of a misguided and tortured showman whose main talent seemed to consist in exploiting his considerable intellect in the corruption of innocent minds with an error-ridden, intoxicating brew of mysticism and linguistic trickery. A few remarks may. perhaps, help towards a more balanced view of Wittgenstein's work than that allowed by Marshall's sadly vacuous 'hatchet job'.

Wittgenstein's later philosophy informs much debate at the interface between the philosophy of mind/language and the special sciences. In particular, the conclusions of his considerations on the nature of rule-following and the normativity of meaning are of some concern in much psychosemantic theory (the discipline concerned with the meaning or 'content' of psychological states), especially the area of biosemantics ${ }^{2}$, and it is a contemporary question whether his insights can be made to cohere with the basic tenets of chomskyan theoretical linguistics ${ }^{3}$.

In addition, the scientific pertinenee of Wittgenstein's writings is also exhibited in the wittgensteinian tenor of Donald Davidson's discussion of the relation between the mental and the physical. in particular the nomological irreducibility of the former to the lattert. Finally. Wittgenstein's remarks on the impossibility of a "private language" constitute a powerful critique of the tendency to offer objectifying accounts of the subjectivity of psychological states, perhaps best exemplified by the uncritical willingness of many scientists to model the cognitive space of the subject, the subject's 'inner life', on the literally inner goings-on of a computer.

Of course, that the brain, as a natural computational mechanism. is the de facto 'seat of consciousness' is undeniable, only the relationship between the two remains stubbornly opaque, except, possibly, for Marshall himself. This is no surprise. however; after all, it was Wittgenstein who said: "someone unpractised in philosophy passes by all the spots where difficulties are hidden in the grass, whereas someone who has had practice will pause and sense that there is a difficulty close by even though he cannot see it yet"s.

A. J. GREENFIELD

Department of Biochemistry and Molecular Genetics.

St Mary's Hospital Medical School, London W2 1PG, UK

Marshal. RePI.IFS-First, "modern philosophers - like Wittgenstein - have no theory of thought to speak of". Second, "in the specific case of Quine and Wittgenstein,

the restrictions that they impose simply exclude from serious study the many fascinating questions they themselves raise"7. Third, in the absence of "any definite conception of body"s, the question of the irreducibility of the mental to the physical cannot even be formulated Fourth, LISP is no more (and no less) a "private language' than is English". Fifth certain aspects of "consciousness" can be studied within the framework of natural science ${ }^{11,11}$. But as Wittgenstein himself wrote: "nothing seems to me less likely than that a scientist or mathematician who reads me should be seriously influenced in the way he works".

The glory of intellectual and cultural life in the Austro-Hungarian Empire had an evil "shadow-side" - apocalyptic kitsch to which Wittgenstein rapidly succumbed and from which he never freed himself. In 1946. he is recommending dropping a few more atom bombs to make an end of "our disgusting soapy water science"s. I rest my case.

Neuropsychology Unit,

University Department of

Clinical Neurology,

The Radcliffe Infirmary,

Oxford OX2 $6 \mathrm{HE}$, UK

1. Marshall. J.C. Nature 347, 435 (1990).

2. Millikan. R.G. Language. Thought and Other Biological Categories (M.IT. Press, 1984)

3. Wright. C. in Reflections on Chomsky (ed. George. A.) (Blackwell. Oxford. 1989)

4. Davidson, D. in Essays on Actions and Events (Oxford University Press, 1986).

5. Wittgenstein. L. Culture and Value (Blackwell. Oxford, 1980) 6. Fodor J A Psychosemantics. The Problem of Meaning in the Philosophy of Mind (MIT. Cambridge, 1987).

Chomsky $N$ in Philosophy. Science and Method (eds

Morgenbesser, S.. Suppes, P. \& White. M.) 260-285 (St Morgenbesser, S.. Suppes.

Martin's, New York, 1969). Cambridge. 1988)

9. Fodor, J.A. The Language of Thought (Crowell, New York 1975)

0.Marshall. J.C. \& Halligan. P.W. Nature 336, 766-767 (1988) 11. Weiskrantz, L. Proc, R. Soc. B239, 247-278 (1990).

\section{Nowhere for the waste?}

SIR-Our striving for a riskless society, coupled with political manoeuvring and a misinformed public, can lead us to heights of absurdity that would be funny were it not for the serious consequences in terms of cost, loss of productivity and misdirected effort. The US policy on the management of low-level radioactive waste (LLRW) is a case in point, with which every researcher who uses radioisotopes ought to be concerned.

Most US users of radioisotopes do not know yet that, unless they happen to live in the northwest or California, radioactive waste generated in their laboratories will have no place to go after 1 January 1993 except perhaps to some interim storage facility on or off-site. This is because the existing waste sites will be required by law to close their doors to non-compact state generators, and other new regional sites have not been built. Congress mandated 11 regional waste sites (compacts) in 1980. Since then, the volume of LLRW has been reduced by 50 per cent. It would make sense to revise the legislation, and reduce the number of sites by consolidating the regions, but few in Congress wish to raise such a controversial issue.

Implementing the "below regulatory concern" (BRC) regulations issued by the NRC would also reduce waste volume by another 30 per cent. In that case, one or two sites could easily handle the LLRW for the entire country. But no sooner had the NRC announced the BRC regulations than Congress began considering legislation to rescind it. $\mathrm{BRC}$ regulations are based on sound, technical grounds, but our politicians seem to know better. They know that $1-10$ mrem per year of additional dose per person as a result of $\mathrm{BRC}$ will endanger our health. But they do not understand that a round-trip coast-to-coast flight will result in similar dose rates or that this additional dose needs to be compared to the 360 mrem per year on the average that each of us is exposed to. They also overlook the fact that the dose rates were derived using extremely conservative models or that the impact of indefinite on-site storage on personnel exposures could be much higher.

17 Galleys Hill Road Extension, Hull, Massachusetts 02045 , USA

\section{Specie not species}

SIR-It is indeed gratifying to read that the nomenclature proposed for the earliest-known reptile is Westlothiana curryi (Nature 346, 399; 1990) and that Wood's name will not be cited in the nomenclature.

I and many others deplore the mercenary aspect that is becoming increasingly prevalent and, as a palaeontologist, I am proud to say that in nearly 50 years of scientific work I have never sold a single fossil - all have been donated to museums and institutions solely in the interests of science.

Nevertheless, the greed that led to a 'value' of $£ 205,000$ being suggested for the reptile should be commemorated in some way. Perhaps a new suborder should be erected for Westlothiana curryi might I suggest Avariceoidea?

46 Brecon Way,

P. J. SMART

Bedford MK41 8DD, UK 